
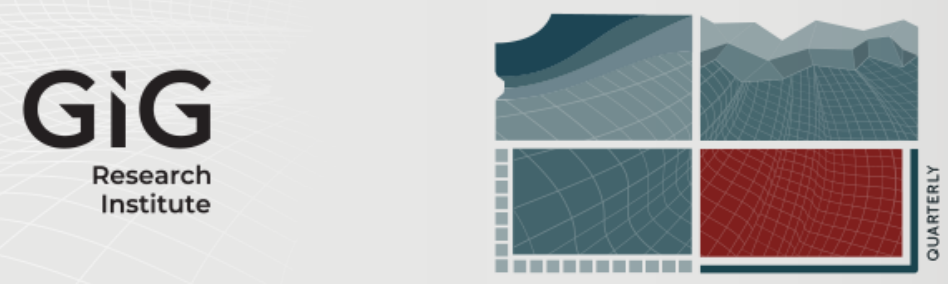

JOURNAL

OF

SUSTAINABLE

MINING

\title{
Determination of the stress-strain state of rock mass and zone of inelastic deformation around underground mine excavation using modern methods of numerical modelling
}

Author(s) ORCID Identifier:

Sergey A. Ignatiev (D) 0000-0002-5527-0978

Aleksandr E. Sudarikov (iD) 0000-0001-9965-2372

Askar Zh. Imashev (D) 0000-0002-9799-8115

Follow this and additional works at: https://jsm.gig.eu/journal-of-sustainable-mining

Part of the Explosives Engineering Commons, Oil, Gas, and Energy Commons, and the Sustainability

\section{Commons}

\section{Recommended Citation}

Ignatiev, Sergey A.; Sudarikov, Aleksandr E.; and Imashev, Askar Zh. (2021) "Determination of the stressstrain state of rock mass and zone of inelastic deformation around underground mine excavation using modern methods of numerical modelling," Journal of Sustainable Mining: Vol. 20 : Iss. 3 , Article 7.

Available at: https://doi.org/10.46873/2300-3960.1324

This Research Article is brought to you for free and open access by Journal of Sustainable Mining. It has been accepted for inclusion in Journal of Sustainable Mining by an authorized editor of Journal of Sustainable Mining. 


\title{
Determination of the stress-strain state of rock mass and zone of inelastic deformation around underground mine excavation using modern methods of numerical modelling
}

\begin{abstract}
The paper reviews methods and trends of numerical modelling of geomechanical processes around underground mine excavations. The most rational method of determining the additional stresses caused by the mine excavations is chosen. Mathematical modelling was performed for excavations of various cross sections and different strength of rocks. The dimensions of the inelastic deformation zone around the mine excavations have been identified. The area of the total fracture zone around the excavation, as well as the area of the roof fracture zone are calculated. The results of the fracture zone modelling are presented both as coordinates and in a graphical form. To simplify application of the modelling results, dependency plots of the obtained parameters were created and analytical dependencies of the fracture zone parameters were identified. The SURFER and KOMPAS software packages were used as the graphic tools to visualize the modelling results
\end{abstract}

\section{Keywords}

rock support, rock mass, surrounding rock mass, geomechanical processes, mathematical modelling, zone of inelastic deformation

\section{Creative Commons License}

(c) (i)

This work is licensed under a Creative Commons Attribution 4.0 License. 


\title{
Determination of the stress-strain state of rock mass and zone of inelastic deformation around underground mine excavation using modern methods of numerical modelling
}

\author{
Sergey A. Ignatiev ${ }^{a} *$, Aleksandr E. Sudarikov ${ }^{a}$, Askar Zh. Imashev ${ }^{b}$ \\ a St. Petersburg Mining University, St. Petersburg, 199106, Russia \\ ${ }^{\mathrm{b}}$ Karaganda Technical University Non-Profit Joint-Stock Company, Karaganda, Kazakhstan
}

\begin{abstract}
The paper reviews methods and trends of numerical modelling of geomechanical processes around underground mine excavations. The most rational method of determining the additional stresses caused by the mine excavations is chosen. Mathematical modelling was performed for excavations of various cross sections and different strength of rocks. The dimensions of the inelastic deformation zone around the mine excavations have been identified. The area of the total fracture zone around the excavation, as well as the area of the roof fracture zone are calculated. The results of the fracture zone modelling are presented both as coordinates and in a graphical form. To simplify application of the modelling results, dependency plots of the obtained parameters were created and analytical dependencies of the fracture zone parameters were identified.
\end{abstract}

The SURFER and KOMPAS software packages were used as the graphic tools to visualize the modelling results.

Keywords: rock support, rock mass, surrounding rock mass, geomechanical processes, mathematical modelling, zone of inelastic deformation

\section{Introduction}

$\mathrm{T}$ he stability of a mine excavation means that the main technological, i.e. load-bearing capacity, and geometric characteristics of the mine support do not change over a certain period of time. In most cases, the excavation retains its basic parameters due to the specific features of the surrounding rock mass or the type of the rock support used. The modern theory of geomechanics distinguishes two main types of retaining technological and geometric parameters of mine excavations. The stability of excavations is maintained without the use of any kind of anchoring or impact on the surrounding rock. This option is suitable for sufficiently strong rock masses that are not considerably fractured and are not subject to weathering. The second case is the use of dedicated load-bearing structures (rock support), which is applied when the rock mass is characterized with low strength, is significantly fractured and is subject to rock strength change under the action of external factors (water, air, etc.).

If the rock mass has the necessary natural stability, no technological support is required for the excavation in these conditions. Stable but naturally or technogenically fractured rocks masses ask for different types of injection support, either chemically or by means of local posts in areas prone to caving. Medium stable, unstable and extremely unstable rocks always require support [1,2].

Studying rock mass stability in underground excavations is the most important scientific and practical task. So far, no single efficient theory of rock stability in underground mining has been proposed. It is explained by the great variety of mining and

Received 22 April 2021; revised 29 July 2021; accepted 30 August 2021.

Available online 12 October 2021

* Corresponding author.

E-mail address: Ignatev_SA@pers.spmi.ru (S.A. Ignatiev). 
geological conditions existing at each operation. Therefore, the main tool in the preliminary design of rock support is the recommendations, in particular, the construction codes of practice. However, the codes themselves indicate the need for additional studies of the factors determining the stability of mine excavations $[3,4]$.

One of the specific features of modern underground construction is constantly increasing complexity of mining, geological and technical conditions of mining activities. This explains why a rational solution to the problems associated with ensuring the stability and reliability of underground excavations, directly depends on the choice of methods to predict and correctly interpret geomechanical processes in the surrounding rock mass.

Creation of any cavity (a mine excavation) can cause either a significant change in the natural stress field inside the rock mass or just its minor alteration. All these changes are highly dependent on the interaction between a large number of factors, which are divided into several segments. In most cases, the segmentation and effects of such factors are highly dependent on the specific conditions of the mine workings. Therefore, it is not always possible to assess the impact of a single segment of conditions on the overall condition of a technogenic cavity [5].

All of this explains why it is practically impossible to account for the impact of a large variety of mining conditions using simple analytical methods and techniques. More advanced methods and models are currently used for more rational and in-depth studies of the surrounding rock mass.

Mining operations always cause changes in the original natural stress- and-strain state of the rock masses. A new stress-and-strain state is always formed around any technogenic underground cavity and excavation, which in some cases may significantly differ from the original one near the mine workings and tend to come to the original natural state only at a considerably long distance from the mine working. In terms of the mine excavations stability, only the adjacent area of the rock mass is of interest, where processes associated with a significant loss of its strength characteristics take place.

If the generated stress-and-strain state of the rock mass around the excavation exceeds the ultimate level, a rock failure will take place, which may develop gradually and smoothly over time and within the rock mass boundaries. This failure will depend on the characteristics of the rocks and the rock support used. In an unfavorable case, the rock failure will be dynamically manifested as rock bursts and blowouts [6].
A number of modelling techniques, which are selected with account for the research goals and tasks, can be used for the up-to-date analysis of geomechanical processes inside the rock mass. The most rational currently used modelling methods are the physical and mathematical modelling. Among the physical modelling methods, the most commonly used are those based on equivalent materials and optically active materials. However, due to the complexity of creating such models and the need for expensive specialized equipment, as well as the significant time spent on producing the model itself, the use of these physical methods is limited and finds its application in the simulation of larger-size objects, e.g. dams, structures with large cross-sections, etc. Therefore, various mathematical models of rock masses provide a more universal and less expensive method of modelling.

In mathematical and numerical modelling of processes that take place inside the rock mass there are three main solution methods: the force method, the displacement method and the mixed method. In solution of geomechanical problems, when analysing the geomechanical processes taking place around the excavations and caused by the rock pressure, the force method is usually used.

In the case of a long excavation which length can exceed its height and width be many times, the volumetric task of calculating stresses and displacements in the surrounding rock mass can be reduced to a two-dimensional problem. Then, any geomechanical problem is reduced to considering the stress and displacement fields around the excavation's cross section only, i.e. to the calculation of stresses around a conditional cross-section of the excavation when the rock mass is considered as a weightless plate which external boundaries extending from the centre of the excavation are loaded with stresses acting in the intact rock mass at the point that corresponds to the centre of the modelled excavation. This calculation scheme is simple and clear, and allows for a sufficiently accurate assessment of stress concentrations in the vicinity of the excavation. The solution will be correct only for excavation's cross sections that remain flat during the deformation process. Such crosssections that are normal to the longitudinal axis should be located at a distance of $1>6 D$ away from the face, where $D$ is the span of the lateral section or the diameter of the excavation with a circular cross section. The error resulting from solving the problem for conditions of flat deformation does not exceed $10 \%$ [3]. 


\section{Materials and methods}

Among the modern numerical methods for solving such problems are the finite difference method (FDM), the finite element method (FEM) and the boundary element method (BEM). Sometimes, engineering methods are used that are based on the combination of theoretical solutions with data from experimental studies and measurements, which allow introduction of correction factors complementing and adjusting the mathematical model to the real-life conditions [7-10].

Nowadays, the most commonly and widely applied method of analytical modelling is the finite element method (FEM), which allows to obtain information on the stress distribution around the mine excavation area when designing various protection solutions. This method is implemented in a number of software packages (ANSYS, Solidworks, Plaxis, etc.). As any other method, it is also not flawless in the way it is applied in the software. Such disadvantages include the fact that the main focus in the software is placed on visualising the problem solutions through coloured zones representing the stress or strain distribution. These FEM drawbacks are inherent in most software products that are based on this method, which significantly limits their application for precise engineering tasks and the design of mine excavations [10,11].

Therefore, in this paper all numerical simulations are performed using the boundary integral equations method, which makes it possible to determine stresses and strains in numeric format at any point of the rock mass. This method is also quite widely used for solving geomechanical problems [12-14].

The research task was set to study the size and shape of the inelastic deformation zone for the arched and trapezoidal shapes of the mine excavations. This problem was solved using mathematical modelling for elastic-plastic settings.

The process of a cavity formation in the rock mass is modelled by a geometric hole of a given shape inside the rock massif, which has a natural stress state. This process induces an increase or redistribution of the initial stress field. These changes (in this case, an increase is assumed) that takes place in the rock mass are divided into several stages. A numerical simulation is performed to determine the stress field in the adopted elastic state of the rock mass characterized with a variable outline at each stage under consideration. At the first stage, this boundary corresponds to the given excavation outline. During the second stage, this outline matches the boundaries of the zone obtained during the previous stage, etc. At each stage, the stresses at the resulting internal boundary shall retain the values reached during the previous stage. Thus, it is assumed that at any loading stage the additional elastic displacements at the inner boundary of the elastic part of the rock mass take place without resistance, as with an unsupported contour (in this case there is no reaction pressure from the rock support). The accumulated displacements of this contour that occurred during the previous loading stages remain unchanged. At each rock mass loading stage, an elastic problem is solved using the boundary integral element method. This method is the most rational and efficient option due to the unpredictable complexity of the intermediate contours of the fracture zone in the course of loading [15].

At all the problem solution stages, the achieved stress-strain condition is assessed using accepted strength criteria. The numerical option does not limit the number of failure criteria, so both the shear (Mohr-Coulomb) and the rupture (highest tensile strains) criteria are used simultaneously [16].

The Mohr-Coulomb rock strength condition is the most commonly used criterion in geomechanical calculations. Since this function was created, and not only has the model preserved its topicality, but it is also constantly used to create new analytical expressions. It is important that, according to Mohr's theory, rock failures occur only due to shear or tensile stresses. The rock mass failure takes place when at least one of the two conditions is met, i.e. excess of tensile or shear stresses (tangential stresses) limit [17-19].

In this or the studied case, the modelling task is to determine the coordinates of the fracture zone boundaries (or the inelastic deformation zone) inside the underground excavation based on the stress-and-strain state of the rock mass. The simulation considered a vertical cross section of the rock mass with a cut which geometry is defined by the typical sections of the excavation, in this case, with an arched profile. The excavation geometry is set as a polygon, which geometry is defined by the coordinates of the nodes, i.e. the polygon vertexes (see Fig. 1). For the solution of this problem we shall limit the scope to a finite series of points located in a strictly defined order. All the investigated points are located along the lines coming from the middle of the plot at a fixed distance from each other. The model is divided into a finite number of segments limited by points with specified coordinates. The number of dividing points remains constant. The length of the dividing intervals is approximately equal to $0.5 \mathrm{~m}$ in all modelling cases. Since a significant accumulation of additional stresses is 


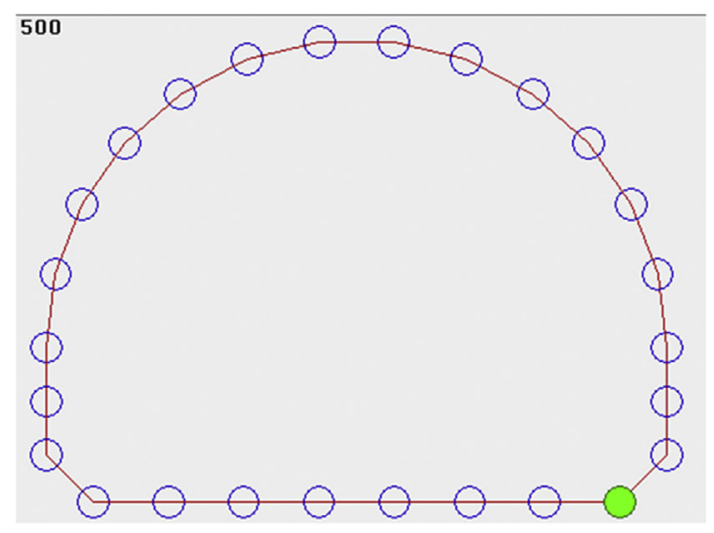

Fig. 1. Node coordinates at the excavation boundaries.

always observed in the corners of the model, all corners of the model were obtruncated, which reflects a more realistic picture of the excavation boundaries [15].

Fig 1 shows a schematic drawing of dividing the excavation into segments (the segments are shown with points along the excavation perimeter) and a schematic diagram of dividing the lines into points with a given step (dividing points are shown with crosses along the line), where the acting stresses are determined. The initial division step and all the subsequent steps are equal to $0.1 \mathrm{~m}$. Fig 2 displays the line inclination angles that are perpendicular to the excavation boundaries and cover the surrounding rock mass in a uniform manner.

The following variables are also input in the computing software to determine the fracture zone: lateral thrust factor $\lambda$, Poisson ratio $v$, dip angle of rock layers $\alpha$, location of rock layers relative to the excavation boundaries, rock cohesion $K$, internal friction angle $\varphi$, ultimate tensile strain $\epsilon_{p}$ of the rock mass layers.

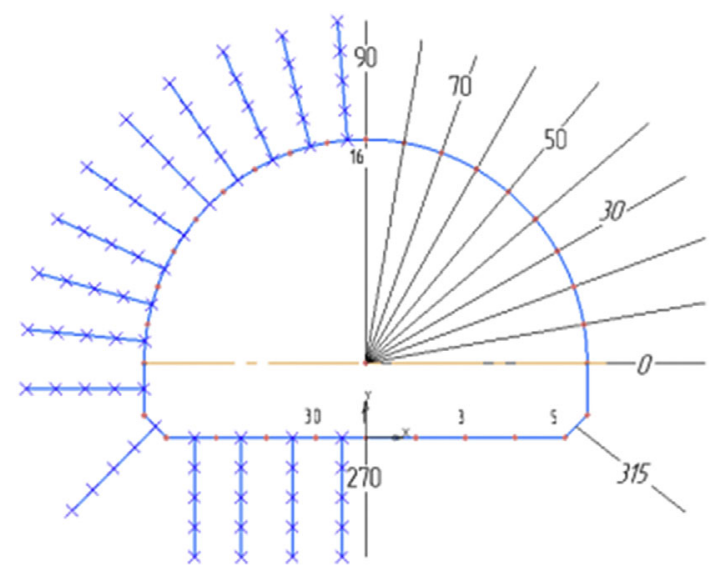

Fig. 2. Layout of lines.
The following input data is also provided: the number of division zones $N$ in the excavation boundaries, and coordinates of each $x_{i}$ and $y_{i}$ line, the line division interval $\delta$ and the number of loading steps $W$. The line orientation should represent a divergent system with uniform coverage of the rock mass. It is also possible to specify the position of the so called weakness planes corresponding to the basic systems of joints.

Studying the impact of joints on the rock strength and, consequently, on the stability of the surrounding rock mass is also of great interest in the design of mine support systems [20,21].

The graphical data for modelling are shown in Fig. 3.

For each of the loading stages, a contour of the zone within which the rocks are in inelastic state is defined. Each stage of the loading study begins with the first line and with the first point on each line, one step away from the view point. Stresses corresponding to the given loading stage are calculated for this point. Upon this, the strength conditions are verified and this operation is repeated for the next point. When all the points along the line are covered, the calculations are done until all the points along all the lines are examined.

With some degree of approximation, the specified strength conditions for rocks can be said to fall within the following ratio: $\sigma_{\text {comp }}: \sigma_{\text {share }}: \sigma_{\text {strain }}=1.0$ : 0.3: 0.1 [21].

In this case, a non-dimensional coefficient $\gamma H / \sigma$ (see Table 1) was taken as the rock strength condition for convenience of calculations.

The results of calculations are the coordinates of the fracture zone boundaries and a graphical

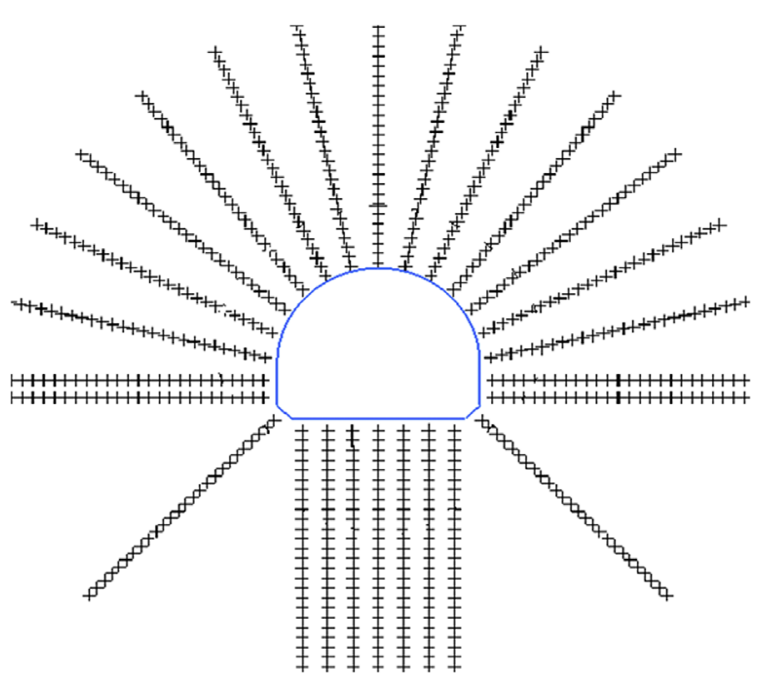

Fig. 3. Graphical data for modelling the arch support. 
Table 1. Rock properties.

\begin{tabular}{|c|c|c|c|c|c|}
\hline$\sigma_{\text {comp. }} \mathrm{MPa}$ & $\gamma H / \sigma_{\text {comp }}$ & $\mathrm{K}_{\mathrm{coh}} \mathrm{MPa}$ & $\sigma_{\text {strain }} \mathrm{MPa}$ & $\begin{array}{l}\frac{\mathrm{K}_{\text {coh }}}{\text { as a s }} \\
\gamma H\end{array}$ & $\frac{\sigma_{\text {strain }}}{\text { nare of }}$ \\
\hline 20 & 0.5 & 7 & 2 & 0.7 & 0.2 \\
\hline 30 & 0.33 & 10 & 3 & 1.0 & 0.3 \\
\hline 40 & 0.25 & 13.3 & 4 & 1.33 & 0.4 \\
\hline 50 & 0.20 & 16.7 & 5 & 1.66 & 0.5 \\
\hline 60 & 0.16 & 20 & 6 & 2 & 0.6 \\
\hline
\end{tabular}

representation of these boundaries around the excavation section (see Figs. 4 and 5).

Having determined the zone of inelastic deformations or the fracture zone, we can assess the size of the fracture zone in the roof, floor and the walls of the excavation, as well as the loads on the mine support from the surrounding rock mass.

In order to obtain numerical values for the support structural load, we need to calculate the size of the fracture zone around the initial excavation. In particular, the vertical support load will be determined by the dimensions of the fracture zone in the roof and the volume weight of the rocks within this fracture zone, i.e. the shaded part of the fracture zone (see Fig. 6).

As a comparison, we also carried out mathematical modelling for a trapezoidal cross-section of the excavation. Some of the results are shown in Figs. 7 and 8.

In order to make the results more demonstrative, we introduced another modelling parameter, i.e. the "excavation impact factor", $K v$, which characterizes the ratio of the total fracture area around the excavation to the area of the excavation.

The area of the roof fracture zone, being the value defining the highest load, can be used to determine the support parameters. However, the predominance of the vertical load over lateral, is not always the case in geomechanics, which should be taken into account when designing the support system.

If bolting can be used as the main support system, then it is possible to use the sizes of the fracture zone in the roof and the walls of the mine excavation to determine the optimal bolt sizes.

Table 2. The values of fracture parameters around the arched section of an underground excavation)

\begin{tabular}{llll}
\hline$\gamma H / \sigma_{\text {comp }}$ & $S v$ & $S k r$ & $K v$ \\
\hline 0.5 & 36.5 & 10.8 & 2.2 \\
0.33 & 20.7 & 7.0 & 1.23 \\
0.25 & 12.6 & 4.6 & 0.76 \\
0.2 & 6.9 & 2.6 & 0.40 \\
0.16 & 1.9 & 1.1 & 0.18 \\
\hline
\end{tabular}

Mine coordinates

$* * 2.00 *-0.50 * * 1.94 *-0.02 * * 1.77 * * 0.45 * * 1.50 * * 0.83 * * 1.14 * * 1.15$

$* * 0.71 * * 1.37 * * 0.24 * * 1.49 *-0.24 * * 1.49 *-0.71 * * 1.37 *-1.14 * * 1.15$

$*-1.50 * * 0.83 *-1.77 * * 0.43 *-1.94 *-0.02 *-2.00 *-0.50 *-2.00 *-0.85$

* $-2.00 *-1.20 *-1.70 *-1.50 *-1.21 *-1.50 *-0.73 *-1.50 *-0.24 *-1.50$

$* * 0.24 *-1.50 * * 0.73 *-1.50 * * 1.21 *-1.50 * * 1.70 *-1.50 * * 2.00 *-1.20$

$* * 2.00 *-0.85 * * 0.00 * * 0.00 * * 0.00 * * 0.00 * * 0.00 * * 0.00 * * 0.00 * * 0.00$

Beam angles

$013 * 026 * 039 * 052 * 065$

$078 * 090 * 102 * 115 * 128$

$141 * 154 * 167 * 180 * 180$

$225 * 270 * 270 * 270 * 270$

$270 * 270 * 270 * 315 * 000$

Solid mass

$1 * *-9.90 * * 2.00 * *-0.58 * * 0.60 * * 0$

Destruction zone coordinates

$* * 2.05 *-0.49 * * 1.98 * * 0.00 * * 1.85 * * 0.49 * * 1.59 * * 0.95 * * 1.20 * * 1.29$

$* * 0.73 * * 1.47 * * 0.24 * * 1.59 *-0.26 * * 1.59 *-0.75 * * 1.46 *-1.20 * * 1.23$

$*-1.58 * * 0.89 *-1.86 * * 0.47 *-2.04 * * 0.00 *-2.10 *-0.50 *-2.20 *-0.85$

* $-2.18 *-1.38 *-1.70 *-1.60 *-1.21 *-1.50 *-0.73 *-1.50 *-0.24 *-1.50$

$* * 0.24 *-1.50 * * 0.73 *-1.50 * * 1.21 *-1.60 * * 1.84 *-1.64 * 2.25 *-1.20$

$* * 2.20 *-0.85$

Fig. 4. Input data and coordinates of the fracture zone.

The data for the arched cross-section was processed as an example to illustrate the results of mathematical modelling.

For this case, based on the values provided in Table 2, graphical dependencies were built and analytical dependencies of the obtained values were found using statistical methods (see Figs. 9 and 10).

The validation criterion for this analytical dependence is the determination factor $R^{2}$. This indicator is a statistical measure of agreement, which helps to determine whether the regression equation corresponds to the actual data. If the determination factor is closer to 1 , it corresponds to a reliable model

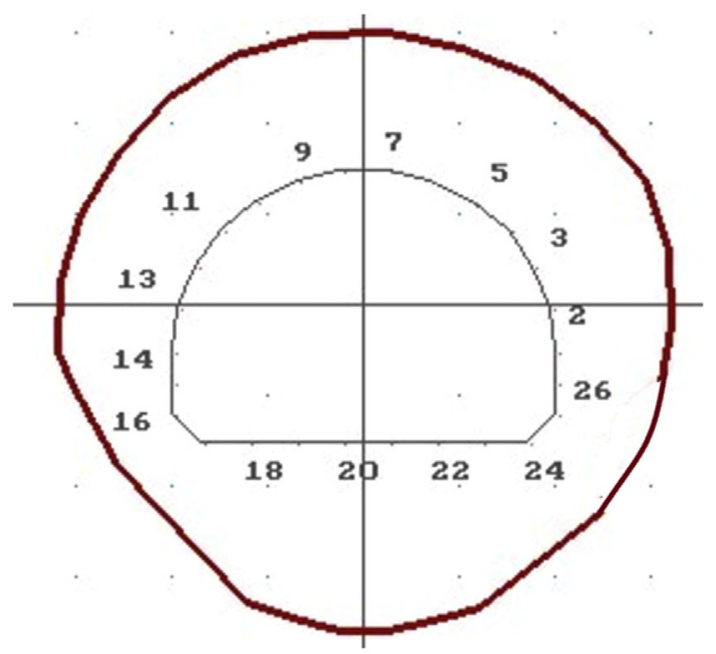

Fig. 5. Graphic representation of the rock fracture zone around an arched-shaped excavation. 


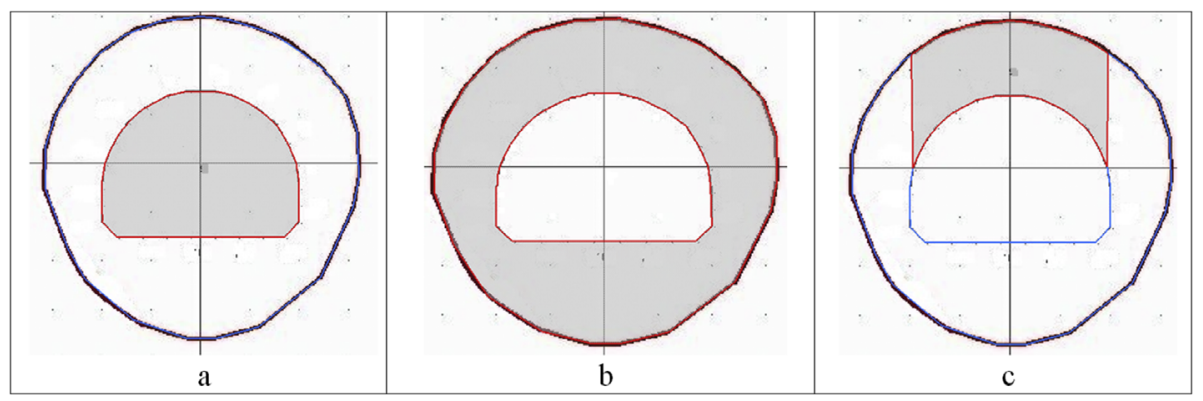

Fig. 6. Numerical definition of the parameters upon mathematical modelling for the arch support: $a$ - the cross-sectional area of the excavation; $b-$ the fracture zone area around the excavation; $c$ - the fracture zone area in the excavation roof.

where all observation points are closer to the regression line [21].

In this case, this parameter is not indicative due to the small number of modelling experiments that were carried out, but it does show the viability of applying this methodology to the modelling results.

It should be emphasised that it is possible to use simple application software to create paired dependencies (as it was demonstrated above). If more complex multivariate mathematical models are to be developed that would reflect several (two or more) parameters as their input indicators, application of more specialised statistical software would be necessary. These software applications make it possible not only to create an analytical relationship between the stability of a mine excavation and input parameters, but also to assess the impact of each of the factors included in the model on the resulting indicator [22].

\section{Results and discussion}

This approach makes it possible to simplify and speed up the process of determining the stresses in the surrounding rock mass, and thus, without the need for mathematical modelling, to determine the most rational parameters of the support system.

However, statistical processing of the obtained results requires a rather significant number of observations and measurements. All of this must be taken into account when building the statistical dependencies of the investigated process.

As Figs. 9 and 10 illustrate, the fracture zone is largely defined by the strength of the surrounding rock mass. If the strength of the rock mass is negligible $(20-30 \mathrm{MPa})$, as can be seen from the drawings, the stability of the mine workings can be ensured by using standing or intensive (retaining frames) support systems. A stronger rock mass (40-60 MPa) around a mine excavation makes it possible to use less expensive enveloping or insulating support (bolting, shotcreting).
It should be particularly noted that this study was not aiming to define rational parameters of the rock support systems for specific rock conditions. The main objective was to demonstrate the algorithm and to determine the parameters of the fracture zone, which can be obtained using a fairly simple computing complex and standard graphics software packages.

A remark can also be made that in some cases, a combination of a sufficiently strong surrounding rock mass weakened by various systems of joints (natural and man-caused), water content in rocks, mutual influence of mine excavations in particular zones, etc., require the use of combined supports that combines properties of several types of the support systems mentioned above.

In order for parameters to be included in a mathematical model, they must be properly studied and expressed not as qualitative indicators, but as quantitative values that can be measured and presented as a number of common measures (strength in $\mathrm{MPa}$, joint spacing, etc.). In any situation, the evaluation of parameters must not be

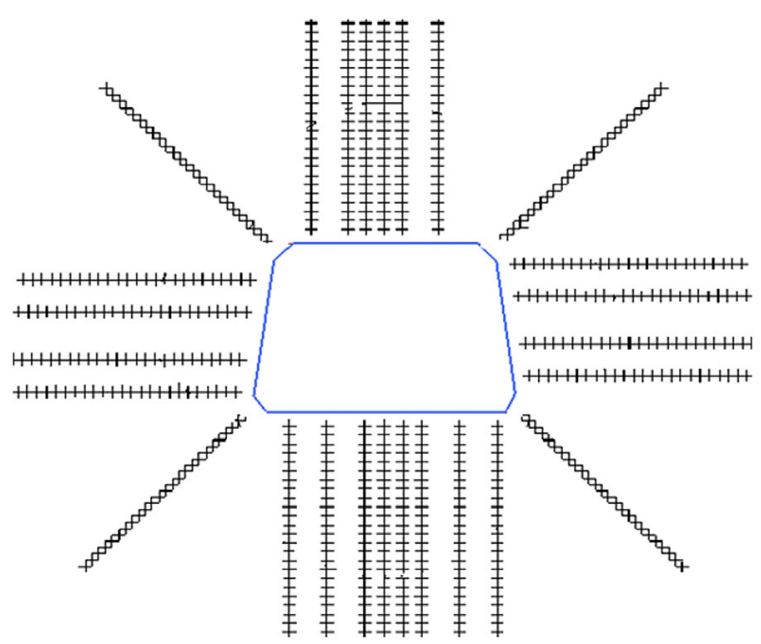

Fig. 7. Input data for modelling of trapezoidal support structures. 


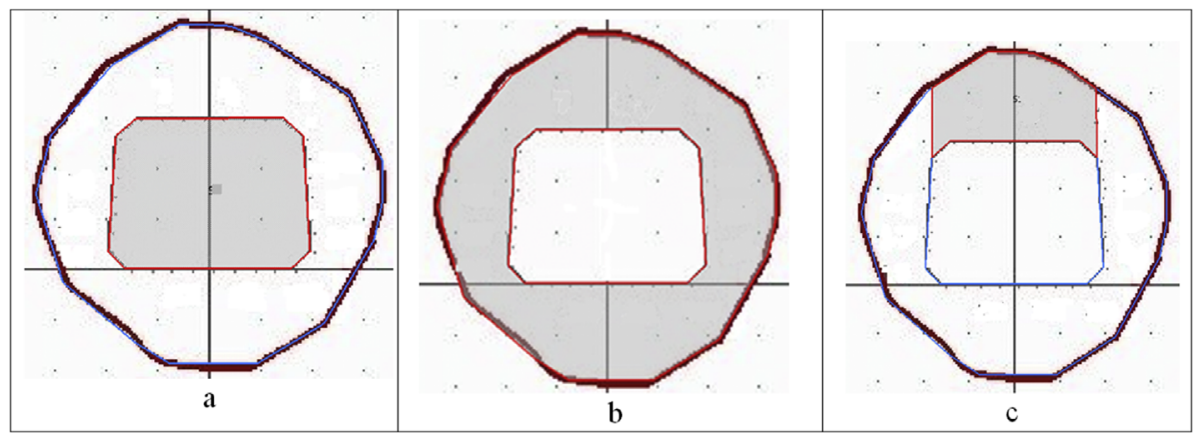

Fig. 8. Numerical definition of the parameters upon mathematical modelling for the trapezoidal support: $a$-the cross-sectional area of the excavation; $b$ - the fracture zone area around the excavation; $c$ - the fracture zone area in the roof of the excavation.

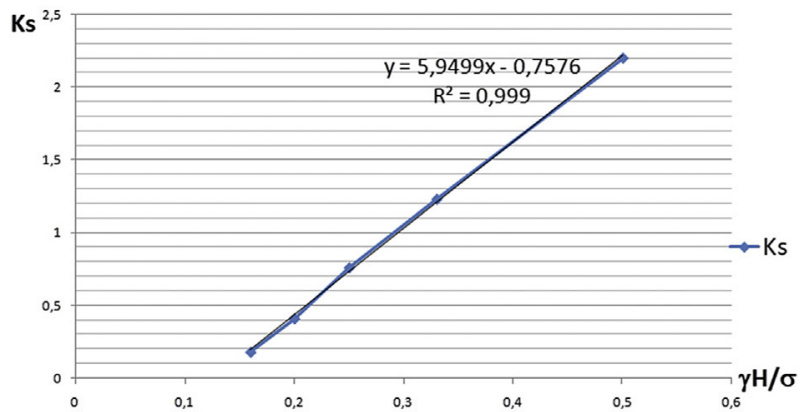

Fig. 9. Graph of the excavation impact factor dependence on $\gamma H / \sigma$.

categorical and unambiguous. Any unambiguous answer may lead to an incorrect interpretation of all the modelling results.

It should also be taken into account that the application of a particular mathematical modelling method cannot be regulated or uniquely defined, since the results depend largely on the objectives pursued, the rock mass condition, the characteristics of the mining operation, as well as the personal preferences or experience of the researcher [23]. In the best-case scenario, mathematical modelling should be used in conjunction with a set of tools and monitoring systems of the surrounding rock mass.
In addition to simple computational complexes, the possibility should be noted to introduce various types of rock mass joints, accounting for possible rock dilatancy in the fracture zone, mutual influence of man-induced baring [24], etc.

However, the use of complex computational complexes and introduction of additional parameters into the initial programme do not always improve the model accuracy and are not necessarily justified in terms of cost and precision of the research. In some cases, a simple solution to an elastic problem can provide a comprehensive answers to the questions posed. It is necessary to do it as simple as possible, but definitely not below the simplicity of this solution.

\section{Conclusions}

Mathematical modelling of the geomechanical processes around the mine excavations makes it possible to take better account of the actual mining environment and thus determine the stability of the surrounding rock mass with the utmost precision.

Monitoring of displacements in the surrounding rock mass due to mining and rock support operations will make it possible to introduce the necessary

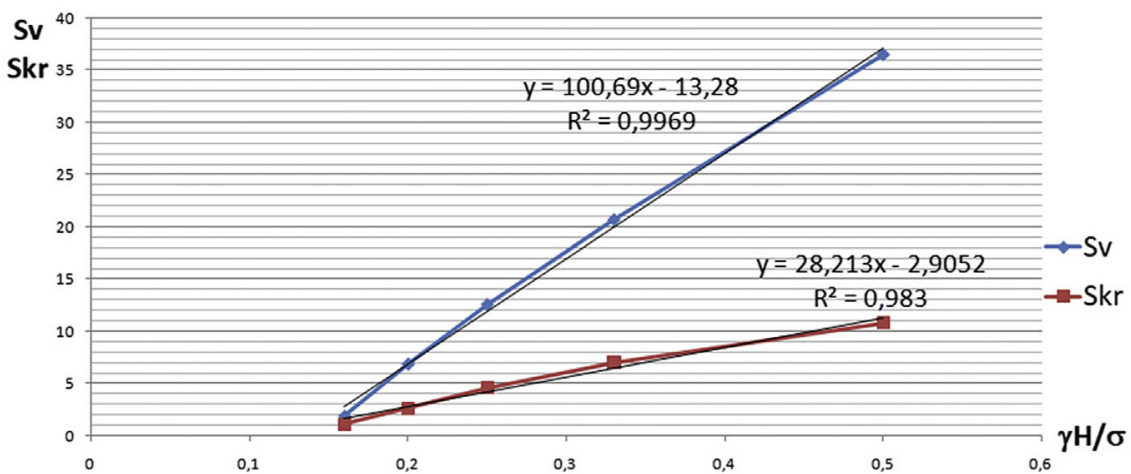

Fig. 10. Graph of the fracture zone area around the excavation, as well as the area of the roof fracture zone calculated depending on $\gamma H / \sigma$. 
corrections and adjustments to the mathematical model, making it the most accurate and closest to the actual settings in a particular mine.

The use of graphical capabilities and the resulting analytical dependencies will help to considerably simplify and speed up the process of determining the stability of mine excavations and develop rational designs of support systems.

Mine support is one of the most expensive and time-consuming operations in mining. Complex research using mathematical modelling and in-situ monitoring of the surrounding rock mass is therefore, in many ways, less expensive than unjustified use of expensive mine support systems.

\section{Conflicts of interest}

None declared.

\section{Ethical statement}

The authors state that the research was conducted according to ethical standards.

\section{Funding body}

None.

\section{Acknowledgments}

The authors are grateful to the head of the Department of Informatics and Computer Technologies Alexei Makhovikov for technical assistance in writing the article. The authors are also grateful to Kirill Fedorov for his help with the translation of the article into English.

\section{References}

[1] https://diss.igduran.ru/sites/default/files/disser/prischepa/ prischepa-disser.pdf.

[2] https://sinref.ru/000_uchebniki/01701gornoe_delo/012 vasuchkov gorn delo/017.htm.

[3] Baklashov I, Kartosia B. Mechanics of underground structures and rock support designs. Moscow: StudentPubl; 2012. p. 543.

[4] SP 91.13330.2012 Underground mine workings. Updated version of SNiP II-94-80.

[5] https://www.dissercat.com/content/sozdanie-metodovobespecheniya-ustoichivosti-gornykh-vyrabotok-rudnikovv-usloviyakh-formiru.
[6] https://www.kazedu.kz/referat/171514.

[7] Trushko V. Development prospects of Geomechanics in conditions of a new technological Mode/V.L.Trushko, A.G. Protosenya. J Minin Inst 2019;236:162-6. https://doi.org/ 10.31897/PMI.2019.2.162.

[8] Karasev M, Buslova M, Wilner M, Nguyen T. Methodology for predicting stress-strain state of vertical shafts support at the intersection with a drift in salt rocks. J Minin Inst 2019, 240:628-37. https://doi.org/10.31897/PMI.2019.6.628.

[9] Kovalski E, Karpov G, Leisle A. Geomechanic models of jointed rock mass/Int J Civ Eng Technol;6(13):440 - 448.

[10] Ilinets A, Sirenko Y, Sidorenko A. Computer modelling of a floor heave in coal mines. J Phys Conf 2019;1333:1-5.

[11] Industrial-wood.ru/zolotorudnye- mestorozhdeniya/14197izuchenie-napryazhennogo-sostoyaniya -massiva-gornyhporod-i-metody- opredeleniya-dopustimyh- parametrovsistem-razrabotki-zolotorudnyh-mestorozhdeniy.html.

[12] Gospodarikov A, Bespalov L. Application of boundary element method to calculate parameters of stress-strain state of rock mass in the vicinity of mine excavations of various profiles. J Minin Inst 2009:217-20. St. Petersburg.

[13] Kolokolov S. Mechanism of fracture zone formation around development workings and their impact on the rock supporting structures. abstract of the thesis for the degree of Doctor of Technical Sciences: 01.02.07. S.B. Kolokolov. AlmaAta; 1992.

[14] Sudarikov A, Muratbakeev E. Analysis of rock mass state around the mine excavations with arched and trapezoidal cross-sections. In: Collection: modern educational technologies in specialists training for mineral resource complex. Collection of research papers of the III All-Russian Scientific Conference; 2020. p. 1043-50.

[15] Imashev A. Justification of stability of technogenic voids in conditions of ushkatyn-3 mine of zhairemsky GOK JSC. Master Degree Thesis. 2010. p. 97. Karaganda,KarGTU.

[16] https://www.kb-sp.ru/informatsiya/geotehnichskaya model_kulona_mora.

[17] Study of compression strength of fractured rock mass/A.G. Protosenya, P.E. Verbilo. J Minin Inst 2017;223:51-7. https:// doi.org/10.18454/PMI.2017.1.

[18] Trushko V, Protosenya A, Verbilo P. Predicting strength of pillars in fractured rock mass during development of apatitenephelinic ores. ARPN J Engin Appl Sci 2018;8(13):2864-72.

[19] Protosenya A, Verbilo P, Karasev M. Research of the mechanical characteristics' anisotropy of apatite-nepheline ores block rock mass. Int J Mech Eng Technol 2018;11(9):1962-72.

[20] https://lektsii.org/8-34598.html.

[21] Kurzaeva L. Regressional analysis in electronic spreadsheets. Int J Appl Basic Res 2016;12-7:1234-8. Available at: https:// applied-research.ru/ru/article/view?id=11019. [Accessed 24 August 2020]. accessed.

[22] Borovikov V. A popular introduction to state-of-the-art data analysis in the STATISTICA system. A training manual for higher education institutions. Moscow, Goriachayaliniya: telekom Publ.; 2013. p. 288.

[23] Ignatiev S, Sudarikov A, Imashev A. Modern mathematical forecast methods of maintenance and support conditions for mining tunnel. J Min Inst 2019;238:371-5.

[24] Sidorenko A, Ivanov V, Sidorenko S. Computer modeling of rock massif stress condition for mining planning on overworked seam. J Phys Conf 2020;1661:1-6. 